\title{
AMENDMENTS
}

\section{Author Correction: Diversity, ecology and evolution of Archaea}

Brett J. Baker (D, Valerie De Anda, Kiley W. Seitz, Nina Dombrowski(D, Alyson E. Santoro and Karen G. Lloyd (1)

Correction to: Nature Microbiology https://doi.org/10.1038/s41564-020-0715-z, published 04 May 2020.

In the version of this Review originally published, the Supplementary Data file included genomes that were mistakenly listed as being acquired from the National Center for Biotechnology Information, genomes that had not been included in the Review and genomes that did not have assigned taxonomy. These genomes have been removed from the file and the updated Supplementary Data is available online.

Published online: 19 May 2020

https://doi.org/10.1038/s41564-020-0741-X

๑) Springer Nature Limited 2020 